\title{
Reducing the burden of maternal and child morbidity and mortality in the Eastern Mediterranean Region? Yes, we can
}

Mahmoud Fahmy Fathalla ${ }^{7}$

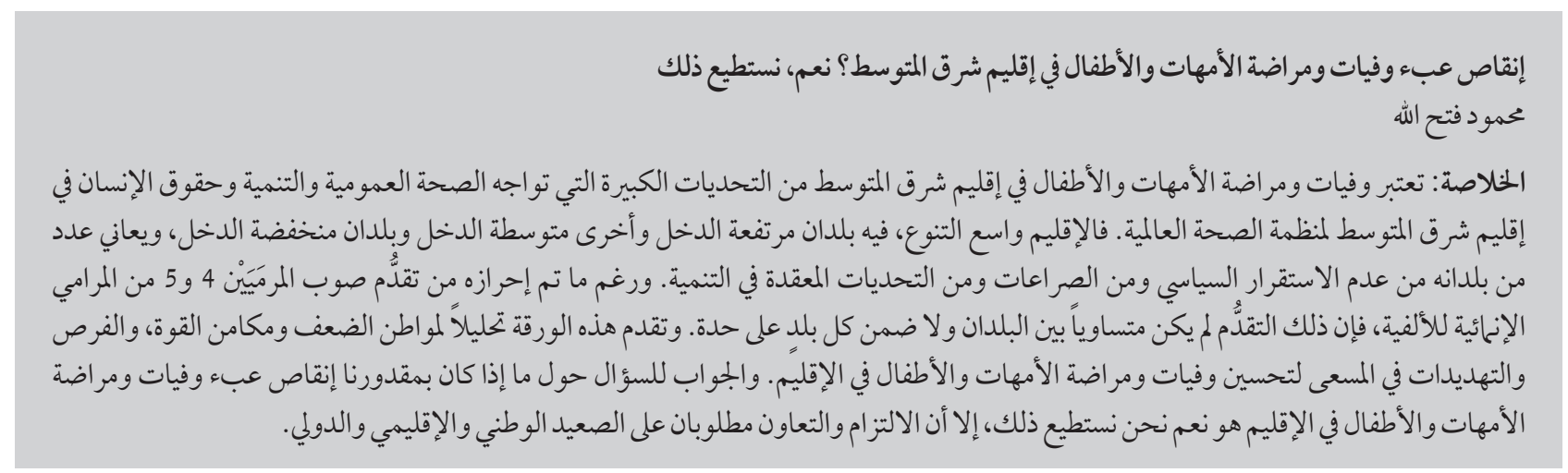

ABSTRACT Maternal and child morbidity and mortality are a major public health, development and human rights challenge globally and in the WHO Eastern Mediterranean Region. The Region is diverse, with high-, middleand low- income countries, many suffering from political instability, conflicts and other complex development challenges. Although progress has been made towards Millennium Development Goals 4 and 5, it has been uneven both between and within countries. This paper makes an analysis of the strengths, weaknesses, opportunities and threats to improving maternal and child mortality and morbidity with a focus on the Region. In answer to the question whether we can reduce the burden of maternal and child morbidity and mortality in the Region: yes, we can. However, commitment and collaboration are needed at the country, regional and international levels.

La réduction de la charge de la morbidité et de la mortalité maternelles et infantiles est effectivement possible dans la Région de la Méditerranée orientale

RÉSUMÉ La morbidité et la mortalité maternelles et infantiles constituent un défi majeur en matière de santé publique, de développement et de droits de l'homme au niveau mondial ainsi que dans la Région OMS de la Méditerranée orientale. La Région est hétérogène et comprend des pays à revenus élevé, intermédiaire et faible, dont plusieurs connaissent une instabilité politique, des conflits ainsi que d'autres problèmes de développement complexes. Malgré les progrès accomplis vers la réalisation des objectifs du Millénaire pour le développement 4 et 5 , des inégalités ont été observées aux niveaux régional et national. Le présent article analyse les forces, faiblesses, opportunités et menaces en matière d'amélioration de la mortalité et de la morbidité maternelles et infantiles dans la Région. La réponse à la question de savoir si nous pouvons effectivement réduire la charge de la morbidité et de la mortalité maternelle et infantile dans la Région est affirmative. Un engagement et une collaboration sont néanmoins nécessaires aux niveaux national, régional et international. 


\section{The challenge}

It is estimated that every year in the WHO Eastern Mediterranean Region (EMR) around 923000 children under 5 years of age still die as a result of common childhood diseases and 39000 women of childbearing age die as a result of pregnancy-related complications [1]. Mortality figures are indicative of a much greater magnitude of morbidity and disability. Maternal and child mortality and morbidity are not only a major public health challenge in the Region and worldwide, they are also a development challenge, explicitly highlighted as 2 of the 8 Millennium Development Goals (MDGs) [2]. Safe motherhood is also a human right of women that should be respected, protected and implemented [3].

EMR is a diverse region that includes high-income countries in which socioeconomic development has progressed considerably over the last 4 decades; middle-income countries which have well-developed health service delivery infrastructures but face resource constraints; and low-income countries which lack resources for health. Many countries of the Region are suffering from political instability, conflicts and other complex development challenges.

Progress in the Region towards the MDGs has been variable [4]. MDG 4, relating to reduction of under 5 mortality, has been achieved by 4 countries only, while another 9 countries are on track and 10 countries are unlikely to achieve the goal, based on current trends. MDG 5, relating to reduction in maternal mortality, has been achieved by 6 countries, while 8 countries are on track and 9 are not expected to achieve the goal, based on current trends. Worldwide, of the 75 countries where more than $95 \%$ of all maternal and child deaths occur, 10 countries are from the Region: Afghanistan, Djibouti, Egypt, Iraq, Morocco, Pakistan, Somalia, South Sudan, Sudan and Yemen [5].

\section{Can we reduce the unacceptable burden of maternal \& child morbidity and mortality in EMR?}

To answer this question we need to undertake a SWOT analysis, to examine our strengths, weaknesses, opportunities and threats, a technique widely used in the business world [6]. Apart from answering the question of feasibility of achieving the goals, the analysis will be useful in guiding the strategy to deal with the challenge. The analysis presented here is not meant to be comprehensive. The aim is to highlight some salient areas for each element of the analysis.

\section{Strengths}

Two areas of strength give us encouragement and confidence. First, evidence-based interventions are already known, have been tested, have been shown to work and can have an impact. Secondly, many countries worldwide in similar socioeconomic situations have achieved success.

\section{Evidence-based interventions are already known}

Evidence-based packages of interventions are already available in a continuum of care for maternal and child health [7]. For safer motherhood, pregnancy must be a voluntary choice for the woman and she should have access to prenatal care, delivery by skilled birth attendants and life-saving emergency obstetric care if needed [8]. Evidencebased interventions are available to deal with the main causes of under-5 child mortality: diarrhoea, pneumonia, measles, malaria, HIV/AIDS, birth asphyxia, preterm delivery, neonatal tetanus and neonatal sepsis. Child survival interventions are feasible to deliver with high coverage in low-income settings [9].

While all elements of the evidencebased packages should be implemented in the Region, 2 areas need more emphasis: family planning and perinatal health. Family planning has an impact on mother and child, apart from other benefits. An unmet need for family planning, particularly for modern methods and for spacing and/or limiting of childbearing, has been demonstrated in countries of the Region where demographic and health surveys have been conducted. The unmet need for family planning ranged from $8 \%$ to $20 \%$ of married women of reproductive age of known fertility [10]. Childhood deaths in EMR are increasingly concentrated in the first month of life [5] and evidence-based interventions need to be intensified to reduce perinatal mortality.

\section{Progress has been made}

Between 1990 and 2011, under-5 mortality declined in EMR by 41\%, maternal mortality declined by 42\% between 1990 and 2010, and the Region witnessed a number of success stories [1]. Exchange of experiences and mutual learning between countries can pay dividends .

\section{Weaknesses}

Two areas of weakness in the EMR should be taken into consideration and need to be addressed. The first is the constraints of the health-care systems. The second is the lack of evidencebased information from countries to guide policy-and decision-making.

\section{Health care systems}

Health systems in the Region face many challenges that are generally crosscutting in nature and apply to most countries irrespective of socioeconomic and health status of their populations [11]. The 3 main inputs needed for a health-care system to function are: human capital, physical capital and consumables [12]. An appropriate balance between these inputs is necessary for good functioning of the system. Investments in these are often imbalanced, however, particularly in countries with limited resources. The bias is towards an 
increased investment in physical capital, at the expense of human capital and consumables. Governments and external aid agencies have contributed to this unbalanced input mix by focusing on highly visible investments without adequate consideration of the need for other investments and the recurrent costs that ensure proper functioning of the system [12]. A health-care system that is sound in structure may not be sound in function, as the experience in some countries has demonstrated [13]: "Good anatomy does not mean good physiology” [14].

The overall health workforce density in the Region is below the global average of 4 skilled health workers per 1000 population. Eight countries (Afghanistan, Djibouti, Iraq, Morocco, Pakistan, Somalia, Sudan and Yemen) are classified as facing a crisis in human resources for health [15].

\section{Evidence-based information for policy- and decision- making}

Almost 40\% of countries in the Region have inadequate or weak civil registration mechanisms and vital statistics, and only $25 \%$ have satisfactory systems. Overall, these systems serve only 5.3\% of the population in the Region [15].

The Commission on Information and Accountability proposed the following core indicators to monitor the impact of interventions and development of programmes: maternal mortality ratio; under-5 mortality rate and the proportion of newborn deaths; children under 5 years of age who are stunted; demand for family planning satisfied (met need for contraception); adequate antenatal care coverage (at least 4 visits during pregnancy); availability of antiretroviral prophylaxis for HIV-positive pregnant women to prevent mother-to-child transmission of HIV and antiretroviral therapy for HIV-positive pregnant women who are treatment-eligible; skilled attendant at birth; postnatal care for mothers and babies within 2 days of birth; exclusive breastfeeding for the first 6 months of life; 3 doses of combined diphtheria-tetanus-pertussis immunization coverage; and availability of antibiotic treatment for pneumonia [5].

When data are collected, they should be viewed and analysed through an equity lens. National averages and overall coverage rates can mask gross inequities. Inequities in health represent the most important challenge facing many countries of the Region [4]. Inequity is particularly evident for interventions that require a functioning health system. Countries achieving rapid progress in intervention coverage have accomplished this primarily by improving coverage in the poorest wealth quintiles [5].

Even when national information systems are lacking, some information can still be gathered and put to use to guide practices, decisions and policies. Confidential enquiries into the causes of cases of maternal mortality provide one such model. They can be conducted at the community, health care facility, district, regional or national level [16]. Experience has shown that the use of these reviews can have a significant impact even without any substantial increase in public expenditure.

\section{Opportunities}

Scientific research, including health systems research, is providing opportunities that can be seized to improve the coverage of maternal and child health services in EMR. These include innovations in technologies appropriate for low-resource settings, and improving service delivery and coverage through task shifting and mobile health initiatives.

\section{Innovations in appropriate technology}

Low-cost innovations, made more available in low-resource countries, can contribute to saving the lives of mothers and children [17]. These include, among others: the non-pneumatic anti-shock garment to slow excessive bleeding after childbirth and stabilize the mother until she can be treated at an emergency care facility; magnesium sulphate, at a cost of less than a dollar per dose, to prevent and treat life-threatening convulsions among women with severe pre-eclampsia and eclampsia; chlorhexidine, a low-cost antiseptic to reduce the risk of life-threatening infections via the newly cut umbilical cord; and Rotavac, an affordable new vaccine to protect children from rotavirus infection, a top cause of deadly diarrhoea in developing countries. So-called "kangaroo care", a way of holding a preterm or full-term infant so that there is skin-to-skin contact between the infant and the person holding it, can be an alternative to neonatal intensive care incubators [18].

\section{Task shifting}

Access to care may be improved by training and enabling mid-level and lay health workers to perform specific interventions that might otherwise be provided by cadres of workers with longer and/or more specialized training. Such task-shifting strategies might be particularly attractive to EMR countries which lack the means to improve access to care within a short period of time. A WHO Guidance Panel made 119 recommendations for appropriate task shifting: 36 for lay health workers, 23 for auxiliary nurses, 17 for auxiliary nurse midwives, 13 for nurses, 13 for midwives, 8 for associate clinicians, 8 for advanced level associate clinicians and 1 for non-specialist doctors [19].

Lay or community health workers, who have not received a formal professional or paraprofessional certificate or tertiary education degree, can be trained and utilized, according to the WHO report, to promote the uptake of maternal and newborn-related health care behaviour and services, to provide continuous social support during labour (in the presence of a skilled birth attendant) and to administer misoprostol to prevent postpartum haemorrhage when 
skilled birth attendants are not present and oxytocin is not available [20].

A number of countries in subSaharan Africa have successfully used non-physicians to perform major emergency obstetrical surgery. In Tanzania, for example, assistant medical officers provide most of this surgery outside of major cities. Studies have demonstrated no significant differences between the care of assistant medical officers and medical officers in terms of outcomes, risk indicators or quality of care [21].

\section{Mobile health (mHealth)}

With over 6 billion mobile phone subscriptions spread across a world population of over 7 billion, mobile technologies are rapidly penetrating even the most remote corners of the world. For women and newborns in many low-and middle-income countries, the rapid expansion of mobile phone technology infrastructure presents an unprecedented opportunity to increase access to health care and to save lives $[22,23]$. Women can be provided with information services by phone. Community-based health workers can be provided with point-of-care decision support tools. Data can also flow through a health system in real-time, and deliver critical information to support women's and providers' needs in a timely and efficient manner. At this time, although mHealth applications are in the formative stage, the evidence for their effectiveness and impact is growing rapidly.

\section{Threats}

Two particular categories of threats in the EMR may be impeding progress towards MDGs 4 and 5. The first includes natural disasters, armed conflicts, and political insecurity and instability. The second is emergence of new health threats. These threats can have a dual impact on maternal and child health: a direct impact on mothers and children who are vulnerable population groups, and an indirect impact by diverting the often limited resources available for maternal and child health.

\section{The threat of natural and man- made disasters}

EMR is a high-risk region for natural hazards such as earthquakes, floods and drought. Political instability and civil conflict are posing new threats. In the past 2 years, 13 countries in the Region have experienced such emergencies, with more than 42 million people affected [15]. Emergency preparedness and response are a priority area for countries in EMR. Disasters, whether natural, or man-made as is often the case, will adversely affect the implementation and achievements of child and maternal health programmes.

Vaccination against poliomyelitis is an example of how armed conflict, insecurity and political instability hinder universal coverage. All countries of the Region are free from polio, except Afghanistan and Pakistan, where conflict, access problems and disinformation among the population have hindered progress in the countries and are posing the threat of spread to other polio-free countries [24].

\section{Emergence of new health threats}

The HIV epidemic has continued to spread through the Region. Although the overall prevalence in the general population is still low, the proportion of newly infected people among all people living with HIV is the highest globally [1]. Where it is prevalent, HIV infection will be an important cause for child and maternal mortality. It can also drain resources from maternal and child health programmes. HIV worldwide has a vocal advocacy constituency, which maternal and child health do not have. The Accountability Commission report for 2013 cites such an example [5]. Although most of the countries reviewed began with low coverage levels for careseeking for pneumonia and for prevention of mother-to-child transmission of HIV, after 5 years the coverage was considerably greater for HIV prevention in every country. Some countries even experienced drops in coverage for pneumonia. The report noted that this was in spite of the fact that pneumonia and diarrhoea together account for 2 million child deaths each year (nearly 15 times the number of child deaths caused by AIDS). The message is not about cutting the resources allocated for HIV, but to call for the same level of attention to be extended to other leading killers of women and children.

Another emerging health threat that is causing considerable concern in the Region is the Middle East respiratory syndrome coronavirus [25].

\section{Yes, we can}

This analysis of the strengths, weaknesses, opportunities and threats answers the question whether we can reduce the burden of maternal and child morbidity and mortality in the Region: yes, we can. But the conclusion has to be qualified. We can, provided we have the commitment and we collaborate together at the country, regional and international level towards the objective.

A solemn commitment to collaboration was made on 30 January 2013 in Dubai, when the ministers of health and delegates of countries of the EMR, representatives of United Nations agencies and international, regional and national institutions participating in the High-level Meeting on Saving the Lives of Mothers and Children: Rising to the Challenge, pledged to "accelerate progress on maternal, newborn, child and adolescent health through national action and international cooperation, to hold themselves accountable for collective progress towards this goal, and on behalf of all mothers, adolescents and children in the Region, recommit to give every woman the best opportunity for safe delivery so that every child has the best possible start in life" [26].

Competing interests: None declared. 
1. Saving the lives of mothers and children. Technical paper submitted to the Sixtieth session of the Regional Committee for the Eastern Mediterranean Region. September 2013. Cairo, World Health Organization Regional Office for the Eastern Mediterranean, 2013 (EM/RC60/3) (http://applications.emro.who. int/docs/RC_Techn_paper_2013_3_15019_EN.pdf, accessed 15 January 2014).

2. Millennium Development Goals (MDGs). World Health Organization [website] (http://www.who.int/topics/millennium_development_goals/en/, accessed 15 January 2014).

3. Fathalla MF. Human rights aspects of safe motherhood. Best Practices and Research in Clinical Obstetrics and Gynaecology, 2006, 20(3):409-419.

4. Shaping the future of health in the WHO Eastern Mediterranean Region: reinforcing the role of WHO. Cairo, World Health Organization Regional Office for the Eastern Mediterranean, 2012 (WHO-EM/RDO/002/E) (http://applications.emro.who.int/ dsaf/EMROPUB_2012_EN_742.pdf, accessed 15 January 2014).

5. Countdown to 2015 for maternal, newborn and child survival. Accountability for maternal, newborn and child survival: the 2013 update. Geneva, World Health Organization/United Nations Children's Fund, 2013.

6. Helms MM, Nixon J. Exploring SWOT analysis-where are we now? A review of academic research from the last decade. Journal of Strategy and Management, 2010, 3:215-251.

7. Bhutta ZA, Black RE. Global maternal, newborn, and child health-so near and yet so far. New England Journal of Medicine, 2013, 369:2226-2235.

8. Fathalla MF. The Hubert de Watteville memorial lecture. Imagine a world where motherhood is safe for all women: you can help make it happen. International Journal of Gynecology and Obstetrics, 2001, 72: 207-213.

9. Jones $\mathrm{G}$ et al. How many child deaths can we prevent this year? Lancet, 2003, 362:65-71.

10. Westoff CF. Unmet need for modern contraceptive methods. Calverton, Maryland, ICF International, 2012 (DHS Analytical Studies No. 28).

11. Health systems strengthening in countries of the Eastern Mediterranean Region: challenges, priorities and options for future action. Technical paper presented to the fifty-ninth session of the WHO Regional Committee for the Eastern Mediterranean. Provisional agenda item 3. February 2013. Cairo, World Health Organization Regional Office for the Eastern Mediterranean, 2012 (EM/RC59/Tech.Disc.1) (http://applications.emro.who. int/docs/RC_technical_papers_2012_Tech_Disc_1_14613_ EN.pdf, accessed 15 January 2014).

12. The world health report 2000. Health systems: improving performance. Geneva, World Health Organization, 2000 (http:// www.who.int/whr/2000/en/, accessed 15 January 2014).

13. Miller S, et al. Quality of care in institutionalized deliveries: the paradox of the Dominican Republic. International Journal of Gynecology and Obstetrics, 2003, 82:89-103.

14. Fathalla MF. Good anatomy does not mean good physiology: commentary on Averting maternal death and disability. International Journal of Gynecology and Obstetrics, 2003, 82:104-106.
15. The work of WHO in the Eastern Mediterranean Region: annual report of the Regional Director, 1 January-31 December 2012. Cairo, World Health Organization Regional Office for the Eastern Mediterranean, 2013 (http://www.emro.who. int/about-who/annual-reports/annual-report-2012html, accessed 15 January 2014).

16. Beyond the numbers-reviewing maternal deaths and complications to make pregnancy safer. Geneva, World Health Organization, 2004.

17. Breakthrough innovations that can save women and children now. Seattle, Washington, Program of Appropriate Technology in Health. (www.path.org/innovations2015/index. php\#innovations, accessed 15 January 2014).

18. Lawn JE et al. Kangaroo mother care' to prevent neonatal deaths due to preterm birth complications. International Journal of Epidemiology, 2010, 39(Suppl. 1):i144-i154.

19. WHO recommendations. Optimizing health worker roles to improve access to key maternal and newborn health interventions through task shifting. Geneva, World Health Organization, 2012 (http://apps.who.int/iris/bitstre am/10665/77764/1/9789241504843_eng.pdf, accessed 15 January 2014).

20. Using lay health workers to improve access to key maternal and newborn health interventions in sexual and reproductive health. Geneva, World Health Organization, 2013 (WHO/ RHR/13.09).

21. Caetano Pereira $\mathrm{C}$ et al. Emergency obstetric surgery by nonphysician clinicians in Tanzania. International Journal of Gynecology and Obstetrics, 2011, 114:180-183.

22. Leveraging mobile technologies to promote maternal and newborn health. The current landscape and opportunities for advancement in low-resource settings. Oakland, California, Center for Innovation and Technology in Public Health, Public Health Institute, 2013 (http://www.phi.org/uploads/application/file s/1cxhw8v7j44po2krpaffkpmr5n3f50ovjld4nhwje27r4pakg4. pdf, accessed 15 January 2014).

23. mHealth: New horizons for health through mobile technologies. Based on the findings of the second global survey on eHealth (Global Observatory for eHealth Series Volume 3) Geneva, World Health Organization, 2012 (http://www.who.int/goe/ publications/goe_mhealth_web.pdf, accessed 15 January 2014).

24. Aylward B. Editorial: an ancient scourge triggers a modern emergency. Eastern Mediterranean Health Journal, 2013, 19:903-904.

25. Middle East respiratory syndrome coronavirus (MERS-CoV) update. 18 November 2013. Global Alert and Response (GAR), World Health Organization [online factsheet] (http://www. who.int/csr/don/2013_11_18/en/index.html, accessed 15 January 2014).

26. Summary report on the high-level meeting on saving the lives of mothers and children: rising to the challenge in the Eastern Mediterranean Region. Dubai, United Arab Emirates 29-30 January 2013. Cairo, World Health Organization Regional Office for the Eastern Mediterranean, 2013 (WHO-EM/WRH/091/E. (http:// applications.emro.who.int/docs/IC_Meet_Rep_2013_ EN_14862.pdf, accessed 15 January 2014). 